\title{
Quantum Chemical Calculations of X-ray Emission
}

\section{Spectroscopy}

\author{
Jack D. Wadey and Nicholas A. Besley*
}

School of Chemistry, University of Nottingham, University Park, Nottingham, NG7 2RD, UK.

E-mail: nick.besley@nottingham.ac.uk

*To whom correspondence should be addressed 


\begin{abstract}
The calculation of X-ray emission spectroscopy with equation of motion coupled cluster theory (EOM-CCSD), time dependent density functional theory (TDDFT) and resolution of the identity single excitation configuration interaction with second order perturbation theory (RI-CIS(D)) is studied. These methods can be applied to calculate X-ray emission transitions by using a reference determinant with a core-hole, and they provide a convenient approach to compute the X-ray emission spectroscopy of large systems since all of the required states can be obtained within a single calculation removing the need to perform a separate calculation for each state. For all of the methods, basis sets with the inclusion of additional basis functions to describe core orbitals are necessary, particularly when studying transitions involving the 1 s orbitals of heavier nuclei. EOM-CCSD predicts accurate transition energies when compared with experiment, however, its application to larger systems is restricted by its computational cost and difficulty in converging the CCSD equations for a core-hole reference determinant, which become increasing problematic as the size of the system studied increases. While RI-CIS(D) gives accurate transition energies for small molecules containing first row nuclei, its application to larger systems is limited by the CIS states providing a poor zeroth order reference for perturbation theory which leads to very large errors in the computed transition energies for some states. TDDFT with standard exchange-correlation functionals predicts transition energies that are much larger than experiment. Optimization of a hybrid and short-range corrected functional to predict the X-ray emission transitions results in much closer agreement with EOM-CCSD. The most accurate exchange-correlation functional identified is a modified B3LYP hybrid functional with $66 \%$ Hartree-Fock exchange, denoted $\mathrm{B}^{66} \mathrm{LYP}$, which predicts X-ray emission spectra for a range of molecules including fluorobenzene, nitrobenzene, acetone, dimethyl sulfoxide and $\mathrm{CF}_{3} \mathrm{Cl}$ in good agreement with experiment.
\end{abstract}

Key Words: X-ray emission spectroscopy, TDDFT, EOM-CCSD, CIS(D) 


\section{Introduction}

In recent years spectroscopy in the X-ray region has become increasingly prominent due to advances in the intensity and resolution obtainable with synchrotron radiation. ${ }^{1}$ Currently, the development of X-ray free-electron lasers that can deliver short femtosecond pulses of hard X-rays has opened up the possibility of time-resolved measurements that hold the promise of resolving ultrafast chemical processes at an atomic level. ${ }^{2}$ Owing to the nature of core orbitals, X-ray spectroscopy can provide a local probe of structure which gives these techniques many advantages compared to more traditional measurements in the ultra-violet. Research in this area has primarily focused on X-ray absorption methods, such as near edge X-ray absorption fine structure (NEXAFS) spectroscopy. NEXAFS spectroscopy corresponds to the structure near the absorption edge arising from the excitation of a core electron to virtual orbitals to form states below the ionisation threshold. NEXAFS spectroscopy probes the unoccupied (or singly occupied) orbitals, while Xray emission spectroscopy (XES), which arises from the decay of valence electrons to fill vacant core orbitals following ionisation of a core electron, provides complementary information by probing the occupied orbitals. Recent applications of XES include probing the bonding in inorganic complexes. $^{3,4}$

The analysis of X-ray spectroscopic data from experiment often relies upon calculations to interpret the structural fingerprint provided by the spectroscopy, and reveal the nature of molecular structure, electronic structure and bonding. This has motivated the development of theoretical methods capable of providing accurate predictions of the spectroscopy given a molecular structure. In the case of X-ray absorption spectroscopy, time-dependent density functional theory (TDDFT) has emerged as an important technique for simulating NEXAFS spectra. ${ }^{5}$ There are a number of techniques used that make the calculation of core excited states efficient within a TDDFT formalism, such as restriction of the excitation subspace (or restricted window TDDFT) ${ }^{6}$ or selectively targeting states within an energy range. ${ }^{7-9}$ One problem that emerges with the application of TDDFT to the calculation of core excited states when using standard exchange-correlation 
functionals is that the predicted excitation energies are considerably lower than those observed in experiment, and this underestimation increases as the nuclear charge on the relevant nuclei increases. $^{10,11}$

This failure of standard functionals can be rationalised through analogy with the more familiar problem of calculating charge transfer transitions within TDDFT. It has been shown that this problem is associated with the self-interaction error in density functional theory (DFT), and if there is low overlap between the donating and accepting orbitals in an electronic excitation then TDDFT with standard functionals will underestimate the excitation energy. ${ }^{12}$ The spatial overlap between orbitals has been used to identify charge transfer transitions and introduce corrections for these states within TDDFT calculations ${ }^{13,14}$ and it also provides the basis for the so-called $\Lambda$ analysis, which provides criteria when generalised gradient approximation (GGA) and hybrid functionals will fail. ${ }^{15}$ Turning to core excited states, it has been shown that these transitions lie well within the region where standard functionals will fail. ${ }^{16}$ This has led to the development of exchange-correlation functionals designed to treat core excited states. These functionals have been based upon modifying the fraction of Hartree-Fock (HF) exchange within a standard hybrid functional, ${ }^{10,11,17}$ and more recently through the development of short-range corrected (SRC) functionals. ${ }^{16} \mathrm{SRC}$ functionals are based upon the following scheme

$$
E_{\mathrm{xc}}^{\mathrm{SRC}}=E_{\mathrm{x}}^{\mathrm{SR}-\mathrm{HF}}+E_{\mathrm{x}}^{\mathrm{LR}-\mathrm{DFT}}+E_{\mathrm{c}}^{\mathrm{DFT}}
$$

combining short-range HF exchange with long-range DFT exchange, and represent a reversal of commonly used long-range corrected functionals. ${ }^{18,19}$ These functionals work by correcting the core orbital energies while not significantly affecting the valence and virtual orbital energies, and have been shown to give accurate core excitation energies and NEXAFS spectra in a range of applications. ${ }^{5,20-23}$ 
In comparison to calculations of NEXAFS spectra, there have been far fewer studies of XES. One approach to computing XES is ligand field multiplet theory (LFMT) and a review on the details of this method can be found elsewhere. ${ }^{24}$ Within this approach a single ion is considered and the chemical environment is then incorporated empirically by introducing the crystal field splittings and the orbital mixing. Alternatively, quantum chemical methods such as HF theory or Kohn-Sham DFT can be applied to compute XES. Within these calculations the energy and matrix elements of the electric dipole moment operator for the various valence to core transitions need to be evaluated. Usually only the electric dipole contributions to the oscillator strength are included since these have been found to be dominant for XES calculations. ${ }^{25}$ Although, in the context of X-ray absorption spectroscopy, it has been shown that for heavier the quadrupole contributions to the intensity are significant. ${ }^{26}$ Within this approach, several different approaches to describing the orbitals of the core-excited state have been used. These include using the frozen orbital approximation where the ground state orbitals are used, ${ }^{25,27-29}$ the $\mathrm{Z}+1$ approximation where an increased nuclear charge is used for the appropriate atom, ${ }^{3}$ a transition potential approach where a half filled core orbital is used providing a balance between final and initial states ${ }^{27}$ and a fully relaxed approach where the orbitals of the core-hole state are optimized in a separate SCF procedure. ${ }^{30,31}$ While all of these approaches have been used successfully, the most theoretically correct is to use orbitals from a fully relaxed core-hole state. However, this method requires a separate SCF calculation for each state of relevance in a spectrum and can introduce undesirable aspects such as the non-orthogonality of the states.

Recently, the calculation of X-ray emission spectra within the equation of motion coupled cluster singles and doubles (EOM-CCSD) method by applying EOM-CCSD to a reference HF wave function with a core-hole. ${ }^{5,32}$ This approach allows the calculation of all relevant states within the same calculation and maintains the orthogonality of the states, in addition to being an accurate method that accounts for electron correlation. This approach was shown to reproduce experimental emission energies typically within a few tenths of an electron volt $(\mathrm{eV})$. However, the wide 
application of this method is limited severely by two factors. Firstly, the computational cost of the method makes the study of large systems, such as transition metal complexes, too expensive. Secondly, converging the CCSD equations for a reference HF determinant with a core-hole proves to be problematic (while converging the HF core-hole wavefunction is straightforward), ${ }^{33}$ and this tends to worsen as the system size increases. Both of the issues would be resolved by adopting a TDDFT approach, but here the challenge is to achieve a similar level of accuracy. A further possibility is CIS(D) which is a second order perturbative approximation to CCSD based upon single excitation configuration interaction (CIS) ${ }^{34,35}$ Current resolution of the identity implementations of this method, denoted RI-CIS(D), are computationally very efficient and can be applied to large systems. CIS(D) has been applied to the study of NEXAFS with limited success, and it was necessary to adopt a scaled opposite spin only approach to reduce the error with experiment and

provide reasonable spectra. ${ }^{36}$ In this paper we investigate the accuracy of TDDFT and CIS(D) for the calculation of XES and explore the modification of exchange-correlation functionals to tailor them for the computation of this type of spectroscopy within a TDDFT framework with the aim of achieving an accuracy comparable to EOM-CCSD at a much lower computational cost.

\section{Computational Methods}

The procedure used for computing X-ray emission energies and the associated spectra can be summarised as follows:

1. Perform a calculation on the neutral ground state molecule.

2. Use the resulting molecular orbitals as the starting point for a further Kohn-Sham or HF SCF calculation on the cation with a core hole in the relevant orbital, invoking an overlap criterion $^{37,38}$ to prevent the collapse of the core hole during the SCF process.

3. Perform a standard TDDFT, RI-CIS(D) or EOM-CCSD calculation and the X-ray emission transitions appear as negative eigenvalues. 
It is possible to use the ground state orbitals for the calculation of the emission energies through bypassing the SCF calculation in step 2, but in this work the relaxation of the orbitals in the presence of the core hole is included. The basis set can play an important role in the accuracy of the calculations and a number of basis sets including 6-311G**, cc-pCVDZ and cc-pCVTZ have been used. ${ }^{39-41}$ A further non-standard basis set, denoted u6-311G**, wherein the basis functions describing the 1s orbitals (not for hydrogen) are uncontracted has also been used. Uncontracting the core basis functions should provide the basis set with a greater flexibility to describe the coreionised state and this basis set has been shown to give a improvement in calculated core-electron binding energies. 38

$\mathrm{X}$-ray emission energies for a range of small molecules involving excitation at the $K$-edge of different nuclei have been computed with EOM-CCSD, RI-CIS(D) and TDDFT. For the TDDFT calculations the Tamm-Dancoff approximation has been used. ${ }^{42}$ The structure of these molecules has been optimised at the MP2/cc-pVTZ level and at the B3LYP/6-311G** level for the larger molecules used in the computation of X-ray emission spectra. The structures have been optimised for the ground state owing to the short lifetime of the core-hole state not allowing sufficient time for relaxation of the structure. For the TDDFT calculations a range of exchange-correlation functionals have been considered including BLYP ${ }^{43,44}$ B3LYP ${ }^{45,46}$ and CAM-B3LYP. ${ }^{19}$ The calculations are non-relativistic and the excitation energies have not been corrected to account for relativistic effects. Relativity has the effect of lowering the core orbital energies relative to the valence orbitals leading to an increase in the transition energies. The magnitude of the this energy increase is reasonably small for the 1s orbitals of first row nuclei, and is often neglected. However, for the 1s orbitals of second row nuclei the effects are large and cannot be neglected. In this work, the accuracy of the TDDFT and RI-CIS(D) excitation energies are assessed relative to the EOM-CCSD values since this reflects the accurate non-relativistic value. Furthermore, the comparison is not limited by the availability of experimental data allowing a wider range of molecules to be studied. 
Exchange-correlation functionals have also been optimised to minimise the mean absolute deviation (MAD) of the computed TDDFT transition energies from their respective EOM-CCSD values. The first functional to be optimised is derived from B3LYP and has the form

$$
\mathrm{BH}^{X} \mathrm{LYP}=X \mathrm{HF}+(0.92-X) \mathrm{B}+0.08 \mathrm{~S}+0.19 \mathrm{VWN}+0.81 \mathrm{LYP}
$$

where HF, B and S are Hartree-Fock, Becke and Slater exchange functionals, and VWN and LYP are correlation functionals, ${ }^{43,44,47,48}$ and the fraction of HF exchange $(X)$ is optimised. This functional form has been used previously to describe core-excitations at the carbon $K$-edge where $X=0.57$ was found to be optimal. ${ }^{17}$ The second functional to be optimised is based upon a SRC functional that has been developed for the calculation of NEXAFS spectra. In this functional, the electron repulsion operator is partitioned according to ${ }^{16}$

$$
\begin{aligned}
\frac{1}{r_{12}} & =C_{\mathrm{SHF}} \frac{\operatorname{erfc}\left(\mu_{\mathrm{SR}} r_{12}\right)}{r_{12}}-C_{\mathrm{SHF}} \frac{\operatorname{erfc}\left(\mu_{\mathrm{SR}} r_{12}\right)}{r_{12}} \\
& +C_{\mathrm{LHF}} \frac{\operatorname{erf}\left(\mu_{\mathrm{LR}} r_{12}\right)}{r_{12}}-C_{\mathrm{LHF}} \frac{\operatorname{erf}\left(\mu_{\mathrm{LR}} r_{12}\right)}{r_{12}}+\frac{1}{r_{12}}
\end{aligned}
$$

Treating the first and third terms of equation 3 with HF exchange and the remaining terms with DFT exchange leads to the following functional

$$
\begin{aligned}
E_{\mathrm{xc}}^{\mathrm{SRC}} & =C_{\mathrm{SHF}} E_{\mathrm{x}}^{\mathrm{SR}-\mathrm{HF}}\left(\mu_{\mathrm{SR}}\right)-C_{\mathrm{SHF}} E_{\mathrm{x}}^{\mathrm{SR}-\mathrm{DFT}}\left(\mu_{\mathrm{SR}}\right) \\
& +C_{\mathrm{LHF}} E_{\mathrm{x}}^{\mathrm{LR}-\mathrm{HF}}\left(\mu_{\mathrm{LR}}\right)-C_{\mathrm{LHF}} E_{\mathrm{x}}^{\mathrm{LR}-\mathrm{DFT}}\left(\mu_{\mathrm{LR}}\right)+E_{\mathrm{x}}^{\mathrm{DFT}}+E_{\mathrm{c}}^{\mathrm{DFT}}
\end{aligned}
$$

where $E_{\mathrm{X}}^{\mathrm{SR}-\mathrm{HF}}$ and $E_{\mathrm{x}}^{\mathrm{LR}-\mathrm{HF}}$ represent the short and long range components of $\mathrm{HF}$ exchange, $E_{\mathrm{x}}^{\mathrm{SR}-\mathrm{DFT}}$ and $E_{\mathrm{x}}^{\mathrm{LR}-\mathrm{DFT}}$ represent the short and long range of DFT exchange and $E_{\mathrm{x}}^{\mathrm{DFT}}$ and $E_{\mathrm{c}}^{\mathrm{DFT}}$ represent DFT exchange and correlation, respectively. This functional has four parameters which can be varied. $C_{\mathrm{SHF}}$ and $C_{\mathrm{LHF}}$ represent the fractions of $\mathrm{HF}$ exchange at $\mathrm{r}_{12}=0$ and $\mathrm{r}_{12}=\infty$, while $\mu_{\mathrm{SR}}$ and $\mu_{\mathrm{LR}}$ are the attenuation parameters in the error functions. It should be noted that these functionals are quite specific in their design and are not recommended for the calculation of other 
properties, where a lower level of accuracy compared to functionals such as B3LYP is expected. All calculations are performed with the Q-Chem software package, ${ }^{49}$ and graphical representation of the spectra is achieved by representing each of the transitions by a Gaussian function with a full width at half maximum of $0.7 \mathrm{eV}$.

\section{Results and Discussion}

Table 1 shows the computed X-ray emission energies and oscillator strengths from EOM-CCSD calculations for a range of molecules comprising atoms from the first row of the periodic table and hydrogen along with the available experimental data. Also shown is an estimate of the correction to the transition energy arising from relativistic effects. This correction is based upon the difference in energy of the 1s orbital in the relevant atom between non-relativistic and relativistic Douglas-Kroll-Hess HF/cc-pCVTZ calculations. ${ }^{38}$ With the $6-311 \mathrm{G}^{* *}$ basis set the MAD between the calculated EOM-CCSD energies and the available experimental data is $0.5 \mathrm{eV}$, however, on incorporating the correction due to relativistic effects this MAD increases to $0.7 \mathrm{eV}$. Uncontracting the $1 \mathrm{~s}$ basis functions gives a consistently lower value for the emission energy and gives a MAD of $0.6 \mathrm{eV}$, although for this basis set the MAD decreases to $0.5 \mathrm{eV}$ when the relativistic correction is included. Consequently, we conclude that the $\mathrm{u} 6-311 \mathrm{G}^{* *}$ basis set provides a more accurate prediction of the non-relativistic emission energies. Even at the EOM-CCSD/u6-311G** level of theory there remains an average error of $0.5 \mathrm{eV}$, while CCSD does not capture all electron correlation effects, the most likely deficiency in the calculations is the basis set and the use of larger basis sets is explored later. Although it should be noted that there can be some uncertainty in the experimental values due to the calibration in the experiments.

The calculated transition energies and the error with respect to the EOM-CCSD values for a representative set of exchange-correlation functionals are shown in Table 2. The results show 
clearly that all three types of functional, generalised gradient approximation (GGA), hybrid and long range corrected, systematically overestimate the transition energies and that the magnitude of the overestimation increases with the nuclear charge of the relevant nuclei. This contrasts with calculations of X-ray absorption where TDDFT with these functionals underestimates the transition energy. The transitions are between an occupied valence orbital and a virtual core orbital and the error can be associated with the energy of the virtual core orbital being too low. The introduction of HF exchange in B3LYP raises the energy of the virtual core orbital (i.e. makes it less negative) and thus reduces the transition energy. Furthermore, there is no significant difference between the B3LYP and CAM-B3LYP results, this is similar to X-ray absorption spectroscopy where the use of a long range corrected functionals has no significant effect on the computed excitation energies. ${ }^{16}$ Also shown in Table 2 are the transition energies computed with RI-CIS(D)/u6-311G** in conjunction with the RIMP2-cc-pVTZ auxiliary basis set. ${ }^{50}$ For the molecules studies, this method provides a good approximation to the EOM-CCSD results with a MAD of $0.4 \mathrm{eV}$. Closer inspection of the results shows that the largest errors are associated with $\mathrm{HCN}$ and $\mathrm{CO}$ which are the two unsaturated molecules. The most serious problem of this method is evident for $\mathrm{CH}_{3} \mathrm{OH}$ where no result is given for the $1 \mathrm{a}^{\prime \prime} \rightarrow 2 \mathrm{a}^{\prime}$ transition. For this transition there is a catastrophic failure, and while the CIS excitation energies are consistent with each other, the (D) correction to the excitation energy of the $1 \mathrm{a}^{\prime \prime} \rightarrow 2 \mathrm{a}^{\prime}$ transition is about $18 \mathrm{eV}$ compared to about $8 \mathrm{eV}$ for the other states. For valence excited states the problem of describing some states with CIS(D) has been attributed to near degeneracy effects and the neglect of double excitations which make the CIS states a poor zeroth order reference for perturbation theory. ${ }^{51}$ However, with the exception of this state, the excitation energies from CIS(D) are in close agreement with EOM-CCSD.

While the long range corrected functional does not improve the computed transition energies, the improvement for B3LYP compared to BLYP does indicate that the presence of HF exchange in the functional is an important factor. Table 3 shows the computed transition energies and associated error when the exchange-correlation functionals have been optimised to minimise the MAD from 
the EOM-CCSD values. For the modified B3LYP functional with a fixed fraction of HF exchange (eqn 2), $66 \%$ is the optimal value for the HF exchange component to give a functional denoted $\mathrm{B}^{66} \mathrm{LYP}$. This reduces the MAD from EOM-CCSD significantly to a value of approximately 0.5 eV. For the SRC functional, optimising the four parameters also gives a MAD of approximately $0.5 \mathrm{eV}$, although marginally larger than for the $\mathrm{B}^{66} \mathrm{LYP}$ functional. This optimisation yields values of $C_{\mathrm{SHF}}=0.71, \mu_{\mathrm{SR}}=0.64 \mathrm{a}_{\mathrm{o}}^{-1}, C_{\mathrm{LHF}}=0.17$ and $\mu_{\mathrm{LR}}=2.45 \mathrm{a}_{\mathrm{o}}^{-1}$. for the four parameters. For both functionals the largest error of about $2 \mathrm{eV}$ is observed for the $5 \sigma \rightarrow 1 \sigma$ transition in $\mathrm{CO}$. It is also important to confirm that the optimisation of the functional has not adversely affected the computed oscillator strengths. The values for the oscillator strengths are given in Tables 1-3 and illustrated in Figure 1 which shows the correlation between the computed EOM-CCSD and DFT oscillator strengths. There is virtually no difference between the computed oscillator strengths for $\mathrm{B}^{66} \mathrm{LYP}$ and the SRC functional, so the results for $\mathrm{B}^{66} \mathrm{LYP}$ are representative of the SRC functional. The two functionals have a similar fraction of HF exchange in the short range, and the key difference in the functionals is that as $r_{12}$ increases the fraction of HF exchange in the SRC functional falls while it remains constant in $\mathrm{B}^{66} \mathrm{LYP}$. The similarity in the computed oscillator strengths of these two functionals, while they both differ from B3LYP, suggests that the short range behaviour of the functional is most important for the calculation of oscillator strengths. For both functionals there is a good correlation with correlation coefficients of 0.87 and 0.88 for the B3LYP and $\mathrm{B}^{66} \mathrm{LYP}$ functionals, respectively. This shows that in parametrizing the functional to optimise the computed transition energies, the accuracy of the computed transition dipole moments has not been unduly affected.

To be widely applicable it is necessary for any method to be able to treat molecules that contain heavier nuclei. Table 4 shows computed EOM-CCSD excitation energies for a set of small molecules containing atoms from the second row of the periodic table together with experimental data for $\mathrm{H}_{2} \mathrm{~S}$ and $\mathrm{CH}_{3} \mathrm{Cl} .{ }^{52,53}$ Since the 1 s orbitals for these atoms will be very compact, the basis set dependence of the the transition energies is explored in more detail. In order to compare the 
results from the calculations with the available experimental data it is necessary to consider the effects of relativity. For the $\mathrm{S}$ and $\mathrm{Cl} K$-edge, the lowering of the $1 \mathrm{~s}$ orbital has been estimated to be $5.9 \mathrm{eV}$ and $7.9 \mathrm{eV}$ for $\mathrm{S}$ and $\mathrm{Cl}$, respectively. ${ }^{16}$ Incorporating this correction with the computed values for best quality basis set cc-pCVTZ gives values of $2466.3 \mathrm{eV}, 2463.0 \mathrm{eV}$ and $2460.2 \mathrm{eV}$ for the transitions in $\mathrm{H}_{2} \mathrm{~S}$, which compares well with the experimental values of $2468.0 \mathrm{eV}, 2463.9$ and $2462.5 \mathrm{eV}$. The agreement with the experimental data for $\mathrm{CH}_{3} \mathrm{Cl}$ is not as good. For the $3 \mathrm{e}_{1} \rightarrow 1 \mathrm{a}_{1}$ transition theory predicts a value of $2816.8 \mathrm{eV}$, very close to the experimental value of $2817.1 \mathrm{eV}$. However, for the $5 \mathrm{a}_{1} \rightarrow 1 \mathrm{a}_{1}$ transition the calculations significantly underestimate the experimental value. Furthermore, the experimental study assigns the band at $2814.1 \mathrm{eV}$ to both $5 \mathrm{a}_{1} \rightarrow 1 \mathrm{a}_{1}$ and $2 \mathrm{e} \rightarrow 1 \mathrm{a}_{1}$ when all the calculations predict a large energy difference between the two transitions. Assessing the effect of using smaller basis sets shows that the computed transition energy is sensitive to the quality of the basis set. With the cc-pCVDZ basis set the computed transition energies are consistently higher by $3-5 \mathrm{eV}$. The computed transition energies for the $\mathrm{u} 6-311 \mathrm{G} * *$ basis set lie between the values obtained with the cc-pCVDZ and cc-pCVTZ basis sets. This suggests that the basis set is approaching the level of accuracy provided by the cc-pCVTZ basis set but at a much reduced computational cost. The exception to this trend is for the $\mathrm{Cl} K$-edge in both $\mathrm{HCl}$ and $\mathrm{CH}_{3} \mathrm{Cl}$ where the transition energies for $\mathrm{u} 6-311 \mathrm{G}^{* *}$ are much higher than those with cc-pCVDZ. It is difficult to rationalise this apparently anomalous behaviour other than to assume that the uncontracted $1 \mathrm{~s}$ orbital in the split valence basis set is not adequately describing the singly occupied 1s orbital.

Table 5 shows the computed transition energies for the excitations from second row nuclei using TDDFT with the modified functionals and RI-CIS(D). TDDFT with the $\mathrm{B}^{66}$ LYP functional gives a MAD from the EOM-CCSD values of about $1.7 \mathrm{eV}$ with the cc-pCVTZ basis set. We note that if the $\mathrm{u} 6-311 \mathrm{G}^{* *}$ basis set is used there is a small worsening in accuracy for all excitations except those at the $\mathrm{Cl} K$-edge where there is a very large deviation of about $18 \mathrm{eV}$ from the EOM-CCSD/cc-pCVTZ calculations. Compared to the transitions involving first row nuclei there 
is an increase in MAD. In the case of X-ray absorption spectroscopy, the fractions of HF exchange required for excitations from first and second row nuclei are significantly different and it is actually surprising that the fraction of HF exchange that is optimal for the first row nuclei performs well for the second row nuclei. Closer observation of the error compared to EOM-CCSD shows a consistent over-estimation of the transition energy, indicating that a slightly greater fraction of HF exchange in the functional should reduce the MAD. Reoptimization of the functional for these transitions leads to at marginally larger fraction of HF exchange, and the $\mathrm{B}^{69} \mathrm{LYP}$ functional has a MAD of $0.7 \mathrm{eV}$. The MAD for the SRC functional is larger than for $\mathrm{B}^{66} \mathrm{LYP}$ at about $2.3 \mathrm{eV}$. This functional consistently underestimates the transition energies, and similar to $\mathrm{B}^{66} \mathrm{LYP}$, optimisation of the functional specifically for second row nuclei will reduce the MAD from EOM-CCSD. The worst performance is shown by RI-CIS(D) which is unexpected based upon the results for the first row nuclei. For these calculations the $\mathrm{u} 6-311 \mathrm{G}^{* *}$ basis set is used in conjunction with the rimp2cc-pVTZ auxiliary basis set, and this results in predictions for the transition energies that are too high. Using the cc-pCVTZ basis set with the rimp2-cc-pVTZ auxiliary basis set has little effect on the computed transition energies, with changes of the order of a few tenths of an $\mathrm{eV}$. The error in these calculations can probably be associated to a large extent with lack of core/valence basis functions in the auxiliary basis set. However, also evident with RI-CIS(D) is its failure for the $6 \mathrm{e} \rightarrow 1 \mathrm{a}_{1}$ in $\mathrm{PF}_{3}$.

For the second row nuclei it is possible to compute lower energy ( $L$-edge) transitions wherein the core-hole is introduced to the $2 \mathrm{~s}$ or $2 \mathrm{p}$ orbitals. For transitions involving a core-hole in the $2 \mathrm{~s}$ orbital, our calculations suggests a significantly smaller dependence on the fraction of HF exchange in the functional compared to the $K$-edge transitions. The transitions energies computed with B3LYP/cc-pCVTZ are typically within $1 \mathrm{eV}$ of those computed with $\mathrm{B}^{66} \mathrm{LYP} / \mathrm{cc}-\mathrm{pCVTZ}$. For example, the computed $2 \mathrm{~b}_{1} \rightarrow 2 \mathrm{a}_{1}, 5 \mathrm{a}_{1} \rightarrow 2 \mathrm{a}_{1}$ and $2 \mathrm{~b}_{2} \rightarrow 2 \mathrm{a}_{1}$ transition energies for $\mathrm{H}_{2} \mathrm{~S}$ are 220.0, 217.1 and 215.1 eV with the B3LYP functional compared to 220.7, 217.4 and $214.6 \mathrm{eV}$ with the $\mathrm{B}^{66} \mathrm{LYP}$ functional. Similarly for $\mathrm{PH}_{3}$, B3LYP gives values of 181.0 and $178.2 \mathrm{eV}$ for 
the $5 \mathrm{a}_{1} \rightarrow 2 \mathrm{a}_{1}$ and $2 \mathrm{e} \rightarrow 2 \mathrm{a}_{1}$ transitions, compared to 181.4 and $177.4 \mathrm{eV}$ with $\mathrm{B}^{66} \mathrm{LYP}$. This weaker dependence on the fraction of HF exchange is likely to be a consequence of the 2 s orbitals in the second row nuclei being significantly less compact than the 1s orbitals resulting in them being less 'core'-like. For calculations involving a core-hole in the 2 p orbitals, spin-orbit coupling effects introduce additional complexity that is not accounted for in the calculations presented here.

Figure 2 shows experimental and computed spectra for a range of larger molecules. For the $\mathrm{C} K$-edge spectra, where there are more than one carbon 1 s orbital, transitions with the core-hole on each of the carbon atoms are computed in separate calculations and combined to give the final spectrum. When computing spectra for larger systems where many transitions are required, we find that RI-CIS(D) commonly gives transition energies that are much too high for some states despite the CIS transition energy being reasonable relative to the other states. Consequently it is difficult to compute spectra with this technique. The $\mathrm{C} K$-edge spectra for fluorobenzene and nitrobenzene reproduce the general shape of the experimental spectra correctly, and there is excellent agreement with experiment for the higher energy bands in acetone and dimethyl sulfoxide. At lower energy experiment shows two distinct bands, while the calculations show only one band. These bands arise from a single transition and there are not two overlapping bands. In EOM-CCSD calculations there are two bands predicted in this region, whereas in the TDDFT calculations the next transition is predicted to be at significantly lower energy. This artefact is not a feature of the $\mathrm{B}^{66} \mathrm{LYP}$ functional and is present in a range of functionals. One possible explanation for this could be that the transition could have multi electron character. For the $\mathrm{F} K$-edge in fluorobenzene the calculations predict bands in the correct place, although the lower energy band is too intense. The experimental spectrum for $\mathrm{CF}_{3} \mathrm{Cl}$ is also reproduced well, the position of the higher energy band is predicted well, although the separation between the two band sin the spectrum is too large with the transition energy of the lower energy band predicted to be too low. Nitrobenzene and phenol show the poorest agreement with experiment even if the satellite lines denoted $S$ are ignored. For these spectra the higher energy bands should be closer together, although the spectra would have a 
closer resemblance to the experiment if a larger bandwidth was used.

\section{Conclusions}

The calculation of X-ray emission spectra with the quantum chemical methods TDDFT, CIS(D) and EOM-CCSD through the application of these techniques to a reference determinant with a core hole has been explored. These methods are advantageous for the calculation of X-ray emission spectra for large systems where many transitions will contribute to the spectra because they do not require separate calculations for each state. While accurate spectra can be obtained through EOMCCSD, its application is limited due to the computational cost and the difficultly in converging the CCSD calculation for the core-hole reference. This motivates the search for methods that can achieve a similar level of accuracy but are computationally cheaper and more robust. RI-CIS(D) predicted accurate transition energies compared to EOM-CCSD for small molecules containing first row nuclei, however, a significantly lower level of accuracy was found for the transitions involving the $1 \mathrm{~s}$ orbitals of second row nuclei. For these transitions, the quality of the basis set used becomes increasingly important and some of this deviation can be attributed to the lack of suitable auxiliary basis sets that account for core-valence correlation. The most problematic aspect of the application of RI-CIS(D) to X-ray emission spectra is the perturbation based correction breaks down for many states making it unreliable for simulating the spectra of relatively large molecules where many transitions are required.

The application of TDDFT with standard exchange-correlation functionals gives transition energies that are too high. Much closer agreement with the transition energies from EOM-CCSD can be achieved with modified exchange-correlation functionals with a greater amount of HF exchange at short range. For transitions involving first row nuclei the modified B3LYP functional with 66\% HF exchange, denoted $\mathrm{B}^{66} \mathrm{LYP}$, is the most accurate. For second row nuclei the accuracy is increased by using a slightly higher amount of HF exchange with the $\mathrm{B}^{69}$ LYP functional. TDDFT 
with these functionals reproduces experimental gas phase spectra for a range of systems, indicating that this method provides an accurate computational approach for simulating the X-ray emission spectra of large systems.

\section{References}

(1) van Bokhoven, J. Phys. Chem. Chem. Phys. 2010, 12, 5502.

(2) Patterson, B.D.; Abela, R. Phys. Chem. Chem. Phys. 2010, 12, 5647-5652.

(3) Smolentsev, G,; Soldatov, A.V.; Messinger, J.;Merz, K.; Weyhermüller, T.; Bergmann, U.; Pushkar, Y.; Yano, J.; Yachandra, V.K.; Glatzel, P. J. Am. Chem. Soc. 2009, 131, 1316113167.

(4) Pollock, C.J.; DeBeer, S. J. Am. Chem. Soc. 2011, 133, 5594-5601.

(5) Besley, N.A.; Asmuruf, F. Phys. Chem. Chem. Phys. 2010, 12, 12024-12039.

(6) Stener, M.; Fronzoni, G.; de Simone, M. Chem. Phys. Lett. 2003, 373, 115-123.

(7) Tsuchimochi, T.; Kobayashi, M.; Nakata, A.; Imamura, Y.; Nakai H. J. Comput. Chem. 2008, 29, 2311-2316.

(8) Schmidt, N.; Fink, R.; Hieringer, W. J. Chem. Phys. 2010, 133, 054703.

(9) Kovyrshin, A.; Neugebauer, J. J. Chem. Phys. 2010, 133, 174114.

(10) Nakata, A.; Imamura, Y.; Ostuka, T.; Nakai, H. J. Chem. Phys. 2006, 124, 094105.

(11) Nakata, A.; Imamura, Y.; Nakai, H. J. Chem. Theory Comput. 2007, 3, 1295-1305.

(12) Dreuw, A.; Weisman, J.; Head-Gordon, M. J. Chem. Phys. 2003, 119, 2943-2946.

(13) Gritsenko, O.; Baerends, E.J.; J. Chem. Phys. 2004, 121, 655-660. 
(14) Neugebauer, J.; Gritsenko, O.; Baerends, E.J.; J. Chem. Phys. 2006, 124, 214102.

(15) Peach, M.J.G.; Benfield, P.; Helgaker, T.; Tozer, D.J. J. Chem. Phys. 2008, 128, 044118.

(16) Besley, N.A.; Peach, M.J.G.; Tozer, D.J. Phys. Chem. Chem. Phys. 2009, 11, 10350-10358.

(17) Besley, N.A.; Noble A. J. Phys. Chem. C 2007, 111, 3333-3400.

(18) Tawada, Y.; Tsuneda, T.; Yanagisawa, S.; Yanai, T.; Hirao, K. J. Chem. Phys. 2004, 120, 8425-8433.

(19) Yanai, T.; Tew, D. P.; Handy, N. C. Chem. Phys. Lett. 2004, 393, 51-57.

(20) Robinson, D; Besley, N. A. Phys. Chem. Chem. Phys. 2010, 12, 9667-9676.

(21) Buckley, M. W. ; Besley, N. A. Chem. Phys. Lett. 2011, 501, 540-546.

(22) Skowron, S. T.; Besley, N. A. Theor. Chem. Acc. 2012, 131, 1267.

(23) Capano, G.; Penfold, T. J.; Besley, N. A.; Milne, C. J.; Reinhard, M.; Rittmann-Frank, H.; Glatzel, P.; Abela, R.; Rothlisberger, U.; Chergui, M.; Tavernelli, I. Chem. Phys. Lett. 2013, 580, 179-184.

(24) de Groot, F. Coord. Chem. Rev. 2005, 249, 31-63.

(25) Lee, N.; Petrenko, T.; Bergmann, U.; Neese, F.; DeBeer, S. J. Am. Chem. Soc. 2010, 132, 9715-9727.

(26) Bernadotte, S.; Atkins, A.J.; Jacob, C.R. J. Chem. Phys. 2012, 137, 204106.

(27) Triguero, L.; Pettersson, L. G. M.; Ågren, H. J. Phys. Chem. A 1998, 102, 10599-10607.

(28) Föhlisch, A.; Hasselström, J.; Bennich, P.; Wassdahl, N.; Karis, O.; Nilsson, A.; Triguero, L.; Nyberg, M.; Pettersson, L. G. M. Phys. Rev. B 2000, 61, 16229-16240.

(29) Gladh, J.; Öberg, H.; Li, J.; Ljungberg, M. P.; Matsuda, A.; Ogasawara, H.; Nilsson, A.; Pettersson, L. G. M.; Öström H. J. Chem. Phys. 2012, 136, 034702. 
(30) Meehan, T. E.; McColl, J.; Larkins, F. P. J. Electron Spectrosc. Relat. Phenom. 1995, 73, 283-292.

(31) Walsh, T. R.; Meehan, T. E.; Larkins, F. P. J. Phys. B.: At. Mol. Opt. Phys. 1996, 29, 207-220.

(32) Besley, N. A. Chem. Phys. Lett. 2012, 542, 42-46.

(33) Ershova, O. V.; Besley, N. A. Chem. Phys. Lett. 2011, 513, 179-183.

(34) Head-Gordon, M.; Rico, R. J.; Oumi, M.; Lee, T. J. Chem. Phys. Lett. 1994, 291, 21-29.

(35) Head-Gordon, M.; Maurice, D.; Oumi, M. Chem. Phys. Lett. 1995, 246, 114-121.

(36) Asmuruf, F. A.; Besley, N. A. Chem. Phys. Lett. 2008, 463, 267-271.

(37) Gilbert, A. T. G.; Besley, N. A.; Gill, P. M. W. J. Phys. Chem. A 2008, 112, 13164-13171.

(38) Besley, N. A.; Gilbert, A. T. G.; Gill, P. M. W. J. Chem. Phys. 2009, 130, 124308.

(39) Krishan, R.; Binkley, J. S.; Seeger, R.; Pople, J. A. textitJ. Chem. Phys. 1980, 72, 650-654.

(40) Dunning Jr., T. H. J. Chem. Phys. 1989, 90, 1007-1023.

(41) Woon, D. E.; Dunning Jr., T. H. J. Chem. Phys. 1993, 98, 1358-1371.

(42) Hirata, S.; Head-Gordon, M. Chem. Phys. Lett. 1999, 314, 291-299.

(43) Becke, A. D. Phys. Rev. A 1988, 38, 3098-3100.

(44) Lee, C. T.; Yang, W. T.; Parr, R. G. Phys. Rev. B 1988, 37, 785-789.

(45) Becke, A. D. J. Chem. Phys. 1993, 98, 5648-5652.

(46) Stephens, P. J.; Devlin, F.J.; Chabalowski, C. F.; Frisch, M. J. J. Phys. Chem. 1994, 98, $11623-11627$.

(47) Dirac, P. A. M. Proc. Cam. Phil. Soc. 1930, 26, 376-385. 
(48) Vosko, S. H.; Will, L.; Nusair, M. Can. J. Phys. 1980, 58, 1200-1211.

(49) Shao, Y.; Molnar, L. F.; Jung, Y.; Kussmann, J.; Ochsenfeld, C.; Brown, S. T.; Gilbert, A. T. B.; Slipchenko, L. V.; Levchenko, S. V.; O’Neill, D. P.; DiStasio Jr, R. A.; Lochan, R. C.; Wang, T.; Beran, G. J. O.; Besley, N. A.; Herbert, J. M.; Lin, C. Y.; Voorhis, T. V.; Chien, S.-H.; Sodt, A.; Steele, R. P.; Rassolov, V. A.; Maslen, P. E.; Korambath, P. P.; Adamson, R. D.; Austin, B.; Baker, J.; Byrd, E. F. C.; Dachsel, H.; Doerksen, R. J.; Dreuw, A.; Dunietz, B. D.; Dutoi, A. D.; Furlani, T. R.; Gwaltney, S. R.; Heyden, A.; Hirata, S.; Hsu, C.-P.; Kedziora, G.; Khalliulin, R. Z.; Klunzinger, P.; Lee, A. M.; Lee, M. S.; Liang, W.; Lotan, I.; Nair, N.; Peters, B.; Proynov, E. I.; Pieniazek, P. A.; Rhee, Y. M.; Ritchie, J.; Rosta, E.; Sherrill, C. D.; Simmonett, A. C.; Subotnik, J. E.; Woodcock III, H. L.; Zhang, W.; Bell, A. T.; Chakraborty, A. K.; Chipman, D. M.; Keil, F. J.; Warshel, A.; Hehre, W. J.; Schaefer III, H. F.; Kong, J.; Krylov, A. I.; Gill, P. M. W.; Head-Gordon, M. Phys. Chem. Chem. Phys. 2006, 8, 3172-3191.

(50) Weigend, F; Köhn, A.; Hättig, C. J. Chem. Phys. 2002, 116, 3175-3183.

(51) Oumi, M.; Maurice, D.; Lee, T. J.; Head-Gordon, M. Chem. Phys. Lett. 1997, 279, 151-157.

(52) Mayer, R.; Lindle, D. W.; Southworth, S. H.; Cowan, P. L. Phys. Rev. A 1991, 43, 235-241.

(53) Lindle, D. W.; Cowan, P. L.; Jach, J.; LaVilla, R. E.; Deslattes, R. D.; Perera, R. C. C. Phys. Rev. A 1991, 43, 2353-2366.

(54) Nordgren, J.; Ågren, H.; Werne, L.O.; Nordling, C.; Siegbahn, K. J. Phys. B: At. Mol. Opt. Phys. 1976, 9, 295-302.

(55) Rubensson, J. E.; Wassdahl, N.; Brammer, R.; Nordgren, J. J. Electron. Spectros. Relat. Phenom. 1988, 47, 131-145.

(56) Glans, P.; La Villa, R. E.; Luo, Y.; Ågren, H.; Nordgren, J. J. Phys. B: At. Mol. Opt. Phys. 1994, 27, 3399-3414. 
(57) Kashtanov, S.; Augustsson, A.; Luo, Y.; Guo, J.-L.; Sathe, C.; Rubensson, J. E.; Siegbahn, H.; Nordgren, J.; Ågren, H. Phys. Rev. B 2004, 69, 024201.

(58) Yumatov, V. D.; Okotrub, A. V.; Furin, G. G.; Salakhutdinov, N. F. Russ. Chem. Bull. 1994, $46,1389-1395$.

(59) Yumatov, V. D.; Okotrub, A. V.; Furin, G. G.; Salakhutdinov, N. F. Russ. Chem. Bull. 1994, 46, 2047-2081.

(60) Yumatov, V. D.; Davydova, N. V.; Furin, G. G. Russ. Chem. Bull. 2006, 55, 1346-1350.

(61) Lange, K. M.; Aziz, E. F. Chem. Soc. Rev. 2013, 42, 6840-6859. 


\begin{tabular}{|c|c|c|c|c|c|}
\hline Excitation & Exp. $^{a}$ & Rel. $^{b}$ & $6-311 \mathrm{G}^{* *}$ & u6-311G** & $f^{c}$ \\
\hline $\mathrm{CH}_{4} 1 \mathrm{t}_{2} \rightarrow 1 \mathrm{a}_{1}$ & 276.3 & 0.1 & 276.2 & 275.8 & 0.031 \\
\hline $\mathrm{CH}_{4} 12 \mathrm{a}_{1} \rightarrow 1 \mathrm{a}_{1}$ & - & 0.1 & 267.0 & 266.6 & 0.000 \\
\hline $\mathrm{CH}_{3} \mathrm{OH} 2 \mathrm{a}^{\prime \prime} \rightarrow 2 \mathrm{a}^{\prime}$ & 281.2 & 0.1 & 279.9 & 279.6 & 0.011 \\
\hline $\mathrm{CH}_{3} \mathrm{OH} 7 \mathrm{a}^{\prime} \rightarrow 2 \mathrm{a}^{\prime}$ & 279.5 & 0.1 & 278.6 & 278.3 & 0.022 \\
\hline $\mathrm{CH}_{3} \mathrm{OH} 6 \mathrm{a}^{\prime} \rightarrow 2 \mathrm{a}^{\prime}$ & 277.4 & 0.1 & 276.5 & 276.2 & 0.025 \\
\hline $\mathrm{CH}_{3} \mathrm{OH} 1 \mathrm{a}^{\prime \prime} \rightarrow 2 \mathrm{a}^{\prime}$ & - & 0.1 & 275.9 & 275.6 & 0.022 \\
\hline $\mathrm{NH}_{3} 2 \mathrm{a}_{1} \rightarrow 1 \mathrm{a}_{1}$ & 395.1 & 0.2 & 395.0 & 394.6 & 0.044 \\
\hline $\mathrm{NH}_{3} 1 \mathrm{e} \rightarrow 1 \mathrm{a}_{1}$ & 388.8 & 0.2 & 388.9 & 388.5 & 0.034 \\
\hline $\operatorname{HCN~} 5 \sigma \rightarrow 1 \sigma$ & - & 0.2 & 393.1 & 392.6 & 0.039 \\
\hline $\operatorname{HCN} 1 \pi \rightarrow 1 \sigma$ & - & 0.2 & 392.2 & 391.6 & 0.028 \\
\hline $\mathrm{H}_{2} \mathrm{O} 1 \mathrm{~b}_{2} \rightarrow 1 \mathrm{a}_{1}$ & 527.0 & 0.4 & 527.7 & 527.1 & 0.042 \\
\hline $\mathrm{H}_{2} \mathrm{O} 3 \mathrm{a}_{1} \rightarrow 1 \mathrm{a}_{1}$ & 525.1 & 0.4 & 525.4 & 524.8 & 0.038 \\
\hline $\mathrm{H}_{2} \mathrm{O} 1 \mathrm{~b}_{1} \rightarrow 1 \mathrm{a}_{1}$ & 521.0 & 0.4 & 521.0 & 520.4 & 0.053 \\
\hline $\operatorname{CO} 5 \sigma \rightarrow 1 \sigma$ & - & 0.4 & 526.6 & 526.0 & 0.018 \\
\hline $\mathrm{CO} 1 \pi \rightarrow 1 \sigma$ & - & 0.4 & 525.7 & 525.2 & 0.043 \\
\hline $\mathrm{CH}_{3} \mathrm{OH} 2 \mathrm{a}^{\prime \prime} \rightarrow 1 \mathrm{a}^{\prime}$ & 527.8 & 0.4 & 528.0 & 527.5 & 0.049 \\
\hline $\mathrm{CH}_{3} \mathrm{OH} 7 \mathrm{a}^{\prime} \rightarrow 1 \mathrm{a}^{\prime}$ & 526.1 & 0.4 & 526.0 & 525.4 & 0.040 \\
\hline $\mathrm{CH}_{3} \mathrm{OH} 6 \mathrm{a}^{\prime} \rightarrow 1 \mathrm{a}^{\prime}$ & 523.9 & 0.4 & 522.2 & 522.0 & 0.023 \\
\hline $\mathrm{HF} 1 \pi \rightarrow 1 \sigma$ & - & 0.6 & 678.5 & 677.9 & 0.057 \\
\hline $\mathrm{HF} 3 \sigma \rightarrow 1 \sigma$ & - & 0.6 & 674.5 & 673.8 & 0.045 \\
\hline $\mathrm{CH}_{3} \mathrm{~F} 2 \mathrm{e} \rightarrow 1 \mathrm{a}_{1}$ & 678.6 & 0.6 & 679.1 & 678.4 & 0.063 \\
\hline $\mathrm{CH}_{3} \mathrm{~F}_{5 \mathrm{a}_{1}} \rightarrow 1 \mathrm{a}_{1}$ & 675.6 & 0.6 & 675.5 & 674.9 & 0.052 \\
\hline MAD & - & - & 0.52 & 0.63 & - \\
\hline MAD (inc relativistic correction) & - & - & 0.67 & 0.51 & - \\
\hline
\end{tabular}

Table 1: Computed EOM-CCSD X-ray emission energies (in eV) for first row molecules. ${ }^{a}$ Experimental data. ${ }^{54-57 b}$ Estimated relativistic correction for the transition energy based upon the lowering of the energy of the $1 \mathrm{~s}$ orbital of the atom. ${ }^{c}$ Oscillator strength computed at the EOM-CCSD/u6-311G** level except for $\mathrm{HCN}$ and $\mathrm{CH}_{3} \mathrm{~F}$ where values from $\mathrm{CIS} / \mathrm{u} 6-311 \mathrm{G}^{* *}$ calculations are shown. 


\begin{tabular}{|c|c|c|c|c|c|}
\hline Excitation & RI-CIS(D) & BLYP & B3LYP & CAM-B3LYP & $f^{a}$ \\
\hline $\mathrm{CH}_{4} 1 \mathrm{t}_{2} \rightarrow 1 \mathrm{a}_{1}$ & $276.4(+0.6)$ & $285.9(+10.1)$ & $282.7(+6.9)$ & $282.5(+6.7)$ & 0.037 \\
\hline $\mathrm{CH}_{4} 12 \mathrm{a}_{1} \rightarrow 1 \mathrm{a}_{1}$ & $267.0(+0.4)$ & $279.2(+12.6)$ & $275.3(+8.7)$ & $275.0(+8.4)$ & 0.000 \\
\hline $\mathrm{CH}_{3} \mathrm{OH} 2 \mathrm{a}^{\prime \prime} \rightarrow 2 \mathrm{a}^{\prime}$ & $279.4(+0.2)$ & $291.1(+11.5)$ & $286.8(+7.2)$ & $286.4(+6.8)$ & 0.008 \\
\hline $\mathrm{CH}_{3} \mathrm{OH} 7 \mathrm{a}^{\prime} \rightarrow 2 \mathrm{a}^{\prime}$ & $278.5(+0.2)$ & $289.6(+11.3)$ & $285.5(+7.2)$ & $285.1(+6.8)$ & 0.020 \\
\hline $\mathrm{CH}_{3} \mathrm{OH} 6 \mathrm{a}^{\prime} \rightarrow 2 \mathrm{a}^{\prime}$ & $277.5(+0.7)$ & $286.9(+10.7)$ & $283.5(+7.3)$ & $283.1(+6.9)$ & 0.032 \\
\hline $\mathrm{CH}_{3} \mathrm{OH} 1 \mathrm{a}^{\prime \prime} \rightarrow 2 \mathrm{a}^{\prime}$ & - & $286.3(+10.7)$ & $282.8(+7.2)$ & $282.5(+6.9)$ & 0.030 \\
\hline $\mathrm{NH}_{3} 2 \mathrm{a}_{1} \rightarrow 1 \mathrm{a}_{1}$ & $394.9(+0.3)$ & $405.2(+10.6)$ & $401.9(+7.3)$ & $401.9(+7.3)$ & 0.049 \\
\hline $\mathrm{NH}_{3} 1 \mathrm{e} \rightarrow 1 \mathrm{a}_{1}$ & $389.1(+0.6)$ & $399.9(+11.4)$ & $396.2(+7.7)$ & $396.1(+7.6)$ & 0.040 \\
\hline $\mathrm{HCN} 5 \sigma \rightarrow 1 \sigma$ & $392.8(+0.2)$ & $404.1(+11.5)$ & $400.6(+8.0)$ & $400.6(+8.0)$ & 0.038 \\
\hline $\mathrm{HCN} 1 \pi \rightarrow 1 \sigma$ & $393.0(+1.4)$ & $403.5(+11.9)$ & $399.6(+8.0)$ & $399.5(+7.9)$ & 0.035 \\
\hline $\mathrm{H}_{2} \mathrm{O} 1 \mathrm{~b}_{2} \rightarrow 1 \mathrm{a}_{1}$ & $527.2(+0.1)$ & $539.1(+12.0)$ & $535.3(+8.2)$ & $535.3(+8.2)$ & 0.059 \\
\hline $\mathrm{H}_{2} \mathrm{O} 3 \mathrm{a}_{1} \rightarrow 1 \mathrm{a}_{1}$ & $524.9(+0.1)$ & $537.4(+12.6)$ & $533.4(+8.6)$ & $533.5(+8.7)$ & 0.048 \\
\hline $\mathrm{H}_{2} \mathrm{O} 1 \mathrm{~b}_{1} \rightarrow 1 \mathrm{a}_{1}$ & $520.7(+0.3)$ & $533.4(+12.6)$ & $529.1(+8.3)$ & $529.2(+8.4)$ & 0.044 \\
\hline $\operatorname{CO} 5 \sigma \rightarrow 1 \sigma$ & $524.0(-2.0)$ & $540.8(+14.8)$ & $534.5(+8.5)$ & $534.2(+8.2)$ & 0.024 \\
\hline $\mathrm{CO} 1 \pi \rightarrow 1 \sigma$ & $525.3(+0.1)$ & $537.9(+12.7)$ & $533.8(+8.6)$ & $533.8(+8.6)$ & 0.049 \\
\hline $\mathrm{CH}_{3} \mathrm{OH} 2 \mathrm{a}^{\prime \prime} \rightarrow 1 \mathrm{a}^{\prime}$ & $527.4(-0.1)$ & $540.5(+13.0)$ & $535.9(+8.4)$ & $535.9(+8.4)$ & 0.051 \\
\hline $\mathrm{CH}_{3} \mathrm{OH} 7 \mathrm{a}^{\prime} \rightarrow 1 \mathrm{a}^{\prime}$ & $525.3(-0.1)$ & $539.5(+14.1)$ & $534.2(+8.8)$ & $534.2(+8.8)$ & 0.039 \\
\hline $\mathrm{CH}_{3} \mathrm{OH} 6 \mathrm{a}^{\prime} \rightarrow 1 \mathrm{a}^{\prime}$ & $521.7(-0.3)$ & $537.0(+15.0)$ & $531.5(+9.5)$ & $531.3(+9.3)$ & 0.022 \\
\hline $\mathrm{HF} 1 \pi \rightarrow 1 \sigma$ & $677.7(-0.2)$ & $691.7(+13.8)$ & $687.3(+9.4)$ & $687.5(+9.6)$ & 0.062 \\
\hline $\mathrm{HF} 3 \sigma \rightarrow 1 \sigma$ & $673.7(-0.1)$ & $688.6(+14.8)$ & $683.8(+10.0)$ & $684.1(+10.3)$ & 0.050 \\
\hline $\mathrm{CH}_{3} \mathrm{~F} 2 \mathrm{e} \rightarrow 1 \mathrm{a}_{1}$ & $678.8(-0.6)$ & $695.2(+16.8)$ & $688.5(+10.1)$ & $688.5(+10.1)$ & 0.040 \\
\hline 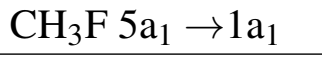 & $674.5(-0.4)$ & $690.8(+15.9)$ & $685.1(+10.2)$ & $685.1(+10.2)$ & 0.047 \\
\hline MAD & 0.44 & 12.75 & 8.37 & 8.28 & - \\
\hline
\end{tabular}

Table 2: Computed X-ray emission energies (in eV) with the $\mathrm{u} 6-311 \mathrm{G}^{* *}$ basis set and the deviation from EOM-CCSD/u6-311G** ${ }^{a} f$ are the oscillator strengths for B3LYP/u6-311G**. 


\begin{tabular}{|c|c|c|c|}
\hline Excitation & $\mathrm{B}^{66} \mathrm{LYP}$ & SRC & $f^{a}$ \\
\hline $\mathrm{CH}_{4} 1 \mathrm{t}_{2} \rightarrow 1 \mathrm{a}_{1}$ & $276.4(0.6)$ & $277.0(1.2)$ & 0.037 \\
\hline $\mathrm{CH}_{4} 12 \mathrm{a}_{1} \rightarrow 1 \mathrm{a}_{1}$ & $267.0(0.4)$ & $267.4(0.8)$ & 0.000 \\
\hline $\mathrm{CH}_{3} \mathrm{OH} 2 \mathrm{a}^{\prime \prime} \rightarrow 2 \mathrm{a}^{\prime}$ & $278.7(-0.9)$ & $279.3(-0.3)$ & 0.027 \\
\hline $\mathrm{CH}_{3} \mathrm{OH} 7 \mathrm{a}^{\prime} \rightarrow 2 \mathrm{a}^{\prime}$ & $278.2(-0.1)$ & $278.9(+0.6)$ & 0.034 \\
\hline $\mathrm{CH}_{3} \mathrm{OH} 6 \mathrm{a}^{\prime} \rightarrow 2 \mathrm{a}^{\prime}$ & $276.1(-0.1)$ & $277.1(+0.9)$ & 0.028 \\
\hline $\mathrm{CH}_{3} \mathrm{OH} 1 \mathrm{a}^{\prime \prime} \rightarrow 2 \mathrm{a}^{\prime}$ & $274.5(-1.1)$ & $275.6(0.0)$ & 0.011 \\
\hline $\mathrm{NH}_{3} 2 \mathrm{a}_{1} \rightarrow 1 \mathrm{a}_{1}$ & $395.3(0.7)$ & $395.5(0.9)$ & 0.050 \\
\hline $\mathrm{NH}_{3} 1 \mathrm{e} \rightarrow 1 \mathrm{a}_{1}$ & $388.5(0.0)$ & $388.6(0.1)$ & 0.040 \\
\hline $\mathrm{HCN} 5 \sigma \rightarrow 1 \sigma$ & $393.5(0.9)$ & $393.4(0.8)$ & 0.040 \\
\hline $\mathrm{HCN} 1 \pi \rightarrow 1 \sigma$ & $391.5(-0.1)$ & $391.6(0.0)$ & 0.034 \\
\hline $\mathrm{H}_{2} \mathrm{O} \quad 1 \mathrm{~b}_{2} \rightarrow 1 \mathrm{a}_{1}$ & $527.6(0.5)$ & $527.7(0.6)$ & 0.059 \\
\hline $\mathrm{H}_{2} \mathrm{O} 3 \mathrm{a}_{1} \rightarrow 1 \mathrm{a}_{1}$ & $525.2(0.4)$ & $525.0(0.2)$ & 0.049 \\
\hline $\mathrm{H}_{2} \mathrm{O} 1 \mathrm{~b}_{1} \rightarrow 1 \mathrm{a}_{1}$ & $520.2(-0.2)$ & $519.9(-0.5)$ & 0.044 \\
\hline $\operatorname{CO} 5 \sigma \rightarrow 1 \sigma$ & $524.1(-1.9)$ & $524.0(-2.0)$ & 0.045 \\
\hline $\operatorname{CO} 1 \pi \rightarrow 1 \sigma$ & $525.3(0.1)$ & $525.2(0.0)$ & 0.050 \\
\hline $\mathrm{CH}_{3} \mathrm{OH} 2 \mathrm{a}^{\prime \prime} \rightarrow 1 \mathrm{a}^{\prime}$ & $527.7(0.2)$ & $527.8(0.3)$ & 0.058 \\
\hline $\mathrm{CH}_{3} \mathrm{OH} 7 \mathrm{a}^{\prime} \rightarrow 1 \mathrm{a}^{\prime}$ & $525.5(0.1)$ & $525.3(0.1)$ & 0.049 \\
\hline $\mathrm{CH}_{3} \mathrm{OH} 6 \mathrm{a}^{\prime} \rightarrow 1 \mathrm{a}^{\prime}$ & $520.9(-1.1)$ & $520.7(-1.3)$ & 0.041 \\
\hline $\mathrm{HF} 1 \pi \rightarrow 1 \sigma$ & $678.5(0.6)$ & $678.3(0.4)$ & 0.063 \\
\hline $\mathrm{HF} 3 \sigma \rightarrow 1 \sigma$ & $674.1(0.3)$ & $673.6(0.2)$ & 0.051 \\
\hline $\mathrm{CH}_{3} \mathrm{~F} 2 \mathrm{e} \rightarrow 1 \mathrm{a}_{1}$ & $678.4(0.0)$ & $678.2(-0.2)$ & 0.061 \\
\hline $\mathrm{CH}_{3} \mathrm{~F} 5 \mathrm{a}_{1} \rightarrow 1 \mathrm{a}_{1}$ & $674.9(0.0)$ & $674.5(0.4)$ & 0.053 \\
\hline MAD & 0.47 & 0.54 & - \\
\hline
\end{tabular}

Table 3: Computed X-ray emission energies (in $\mathrm{eV}$ ) for the optimised exchange-correlation functionals with the $\mathrm{u} 6-311 \mathrm{G} * *$ basis set and the deviation from EOM-CCSD/u6-311G** ${ }^{a} f$ are the oscillator strengths for $\mathrm{B}^{66} \mathrm{LYP} / \mathrm{u} 6-311 \mathrm{G}^{* *}$. 


\begin{tabular}{|c|c|c|c|c|}
\hline Excitation & ${ }^{a}$ Exp. & u6-311G** & cc-pCVDZ & cc-pCVTZ \\
\hline $\mathrm{SiH}_{4} 2 \mathrm{t}_{2} \rightarrow 1 \mathrm{a}_{1}$ & & 1829.7 & 1831.5 & 1828.6 \\
$\mathrm{SiH}_{4} 3 \mathrm{a}_{1} \rightarrow 1 \mathrm{a}_{1}$ & & 1823.6 & 1825.4 & 1822.6 \\
$\mathrm{PH}_{3} 5 \mathrm{a}_{1} \rightarrow 1 \mathrm{a}_{1}$ & & 2135.0 & 2136.8 & 2133.9 \\
$\mathrm{PH}_{3} 2 \mathrm{e} \rightarrow 1 \mathrm{a}_{1}$ & & 2130.8 & 2132.7 & 2129.8 \\
$\mathrm{PF}_{3} 8 \mathrm{a}_{1} \rightarrow 1 \mathrm{a}_{1}$ & & 2139.1 & 2141.2 & 2138.7 \\
$\mathrm{PF}_{3} 1 \mathrm{a}_{2} \rightarrow 1 \mathrm{a}_{1}$ & & 2132.9 & 2135.1 & 2132.4 \\
$\mathrm{PF}_{3} 6 \mathrm{e} \rightarrow 1 \mathrm{a}_{1}$ & & 2132.7 & 2134.9 & 2132.1 \\
$\mathrm{H}_{2} \mathrm{~S} 2 \mathrm{~b}_{1} \rightarrow 1 \mathrm{a}_{1}$ & 2468.0 & 2461.5 & 2462.9 & 2460.4 \\
$\mathrm{H}_{2} \mathrm{~S} 5 \mathrm{a}_{1} \rightarrow 1 \mathrm{a}_{1}$ & 2463.9 & 2458.2 & 2459.6 & 2457.1 \\
$\mathrm{H}_{2} \mathrm{~S} 2 \mathrm{~b}_{2} \rightarrow 1 \mathrm{a}_{1}$ & 2462.5 & 2455.2 & 2456.7 & 2454.3 \\
$\mathrm{CH}_{3} \mathrm{SH} 3 \mathrm{a}^{\prime \prime} \rightarrow 1 \mathrm{a}_{1}$ & & 2461.5 & 2462.9 & 2460.5 \\
$\mathrm{CH}_{3} \mathrm{SH} 10 \mathrm{a}^{\prime} \rightarrow 1 \mathrm{a}_{1}$ & & 2458.5 & 2459.8 & 2457.5 \\
$\mathrm{CH}_{3} \mathrm{SH} 9 \mathrm{a}^{\prime} \rightarrow 1 \mathrm{a}_{1}$ & & 2455.8 & 2457.2 & 2454.9 \\
$\mathrm{HCl} 2 \pi \rightarrow 1 \sigma$ & & 2816.0 & 2810.3 & 2808.0 \\
$\mathrm{HCl}_{5} \sigma 1 \sigma$ & & 2811.6 & 2805.9 & 2803.6 \\
$\mathrm{CH}_{3} \mathrm{Cl} 3 \mathrm{e}_{1} \rightarrow 1 \mathrm{a}_{1}$ & 2817.1 & 2817.2 & 2812.2 & 2808.9 \\
$\mathrm{CH}_{3} \mathrm{Cl} 5 \mathrm{a}_{1} \rightarrow 1 \mathrm{a}_{1}$ & 2814.1 & 2809.9 & 2805.0 & 2801.7 \\
$\mathrm{CH}_{3} \mathrm{Cl} 2 \mathrm{e} \rightarrow 1 \mathrm{a}_{1}$ & & 2805.3 & 2800.2 & 2796.9 \\
\hline
\end{tabular}

Table 4: Basis set dependence of the computed EOM-CCSD emission energies (in eV). ${ }^{a}$ Experimental data. ${ }^{52,53}$ 


\begin{tabular}{|c|c|c|c|c|}
\hline Excitation & $\mathrm{B}^{66} \mathrm{LYP}$ & $\mathrm{B}^{69} \mathrm{LYP}$ & $\mathrm{SRC}$ & RI-CIS(D) \\
\hline $\mathrm{SiH}_{4} 2 \mathrm{t}_{2} \rightarrow 1 \mathrm{a}_{1}$ & $1829.0(+0.4)$ & $1827.3(-1.3)$ & $1825.4(-3.2)$ & $1833.6(+5.0)$ \\
$\mathrm{SiH}_{4} 3 \mathrm{a}_{1} \rightarrow 1 \mathrm{a}_{1}$ & $1823.3(+0.7)$ & $1821.5(-1.1)$ & $1820.2(-2.4)$ & $1827.2(+4.6)$ \\
$\mathrm{PH}_{3} 5 \mathrm{a}_{1} \rightarrow 1 \mathrm{a}_{1}$ & $2135.7(+1.8)$ & $2133.9(+0.0)$ & $2131.4(-2.5)$ & $2138.1(+4.2)$ \\
$\mathrm{PH}_{3} 2 \mathrm{e} \rightarrow 1 \mathrm{a}_{1}$ & $2131.2(+1.4)$ & $2129.3(-0.5)$ & $2127.2(-2.6)$ & $2134.7(+4.9)$ \\
$\mathrm{PF}_{3} 8 \mathrm{a}_{1} \rightarrow 1 \mathrm{a}_{1}$ & $2140.0(+1.3)$ & $2138.3(-0.4)$ & $2135.5(-3.2)$ & $2142.3(+3.6)$ \\
$\mathrm{PF}_{3} 1 \mathrm{a}_{2} \rightarrow 1 \mathrm{a}_{1}$ & $2132.4(+0.0)$ & $2130.3(-2.1)$ & $2129.3(-3.1)$ & $2139.8(+7.4)$ \\
$\mathrm{PF}_{3} 6 \mathrm{e} \rightarrow 1 \mathrm{a}_{1}$ & $2132.2(+0.1)$ & $2130.1(-2.0)$ & $2129.1(-3.0)$ & - \\
$\mathrm{H}_{2} \mathrm{~S} 2 \mathrm{~b}_{1} \rightarrow 1 \mathrm{a}_{1}$ & $2462.7(+2.3)$ & $2460.8(+0.4)$ & $2458.2(-2.2)$ & $2464.2(+3.8)$ \\
$\mathrm{H}_{2} \mathrm{~S} 5 \mathrm{a}_{1} \rightarrow 1 \mathrm{a}_{1}$ & $2459.3(+2.2)$ & $2457.4(+0.3)$ & $2454.8(-2.3)$ & $2461.0(+3.9)$ \\
$\mathrm{H}_{2} \mathrm{~S} 2 \mathrm{~b}_{2} \rightarrow 1 \mathrm{a}_{1}$ & $2456.1(+1.8)$ & $2454.1(-0.2)$ & $2451.8(-2.5)$ & $2458.7(+4.4)$ \\
$\mathrm{CH}_{3} \mathrm{SH} 3 \mathrm{a}^{\prime \prime} \rightarrow 1 \mathrm{a}_{1}$ & $2462.7(+2.2)$ & $2460.8(+0.3)$ & $2458.2(-2.3)$ & $2464.2(+3.7)$ \\
$\mathrm{CH}_{3} \mathrm{SH} 10 \mathrm{a}^{\prime} \rightarrow 1 \mathrm{a}_{1}$ & $2459.6(+2.1)$ & $2457.6(+0.1)$ & $2455.2(-2.3)$ & $2461.4(+3.9)$ \\
$\mathrm{CH}_{3} \mathrm{SH} 9 \mathrm{a}^{\prime} \rightarrow 1 \mathrm{a}_{1}$ & $2456.7(+1.8)$ & $2454.9(+0.0)$ & $2452.5(-2.4)$ & $2459.3(+4.4)$ \\
$\mathrm{HCl} 2 \pi \rightarrow 1 \sigma$ & $2811.0(+3.0)$ & $2809.0(+1.0)$ & $2806.4(-1.6)$ & $2815.0(+7.0)$ \\
$\mathrm{HCl} 5 \sigma \rightarrow 1 \sigma$ & $2806.4(+2.8)$ & $2804.6(+1.0)$ & $2801.7(-1.9)$ & $2810.6(+7.0)$ \\
$\mathrm{CH}_{3} \mathrm{Cl} 3 \mathrm{e}_{1} \rightarrow 1 \mathrm{a}_{1}$ & $2811.9(+3.0)$ & $2809.8(+0.9)$ & $2807.3(-1.6)$ & $2816.2(+7.3)$ \\
$\mathrm{CH}_{3} \mathrm{Cl} 5 \mathrm{a}_{1} \rightarrow 1 \mathrm{a}_{1}$ & $2804.8(+3.1)$ & $2802.7(+1.0)$ & $2800.4(-1.3)$ & $2808.6(+6.9)$ \\
$\mathrm{CH}_{3} \mathrm{Cl} 2 \mathrm{e} \rightarrow 1 \mathrm{a}_{1}$ & $2799.1(+2.2)$ & $2796.8(-0.1)$ & $2795.2(-1.7)$ & $2807.1(+10.2)$ \\
\hline $\mathrm{MAD}$ & 1.67 & 0.71 & 2.34 & 5.42 \\
\hline
\end{tabular}

Table 5: Computed X-ray emission energies (in eV) for RI-CIS(D) and TDDFT with the optimised exchange-correlation functionals. The calculations used the cc-pCVTZ basis set and the deviation from the EOM-CCSD/cc-pCVTZ values are shown. 

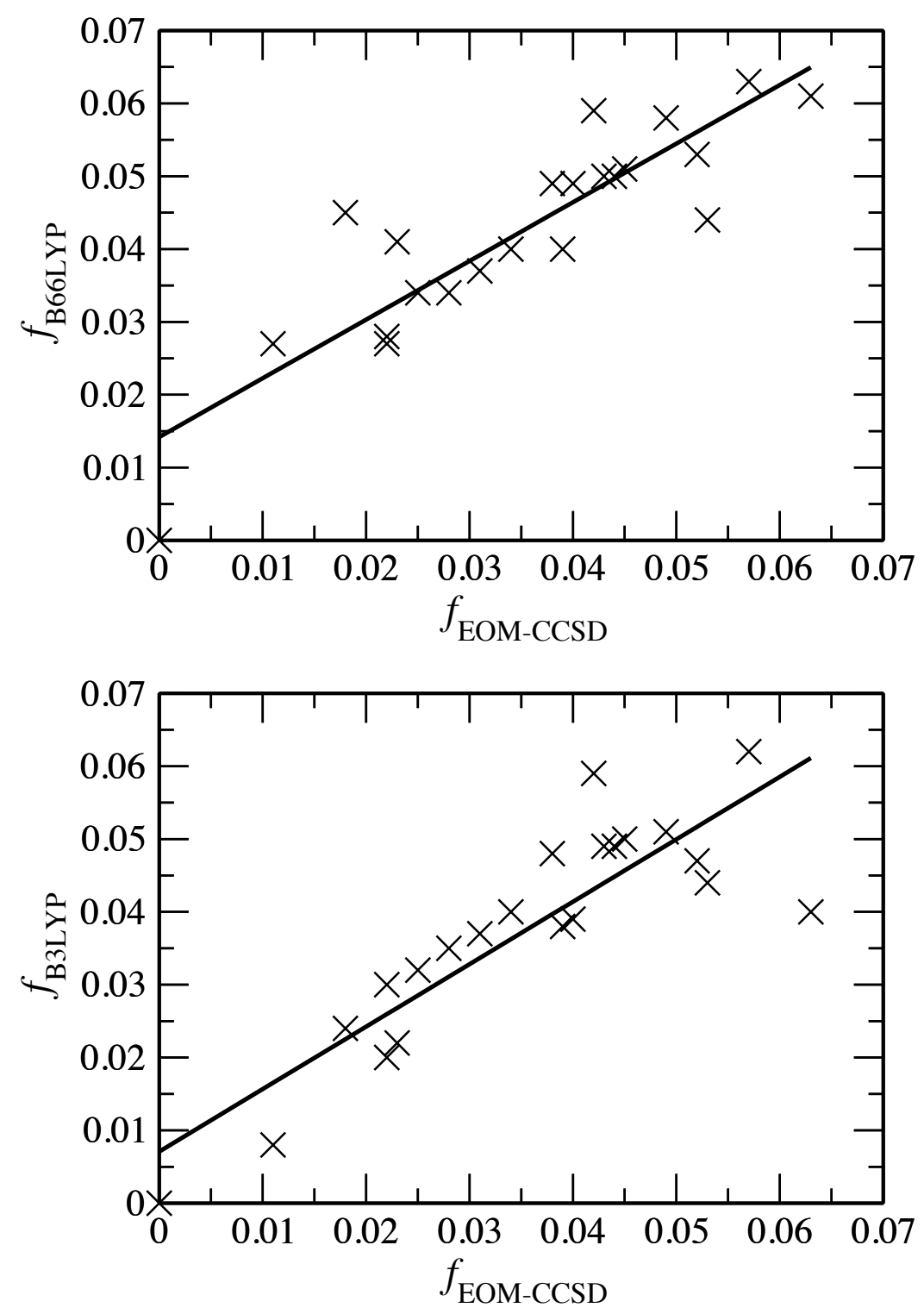

Figure 1: Correlation between the computed EOM-CCSD and B ${ }^{66} \mathrm{LYP}$ (upper panel) and B3LYP (lower panel) oscillator strengths. The transitions are ordered according to increasing EOM-CCSD values. 


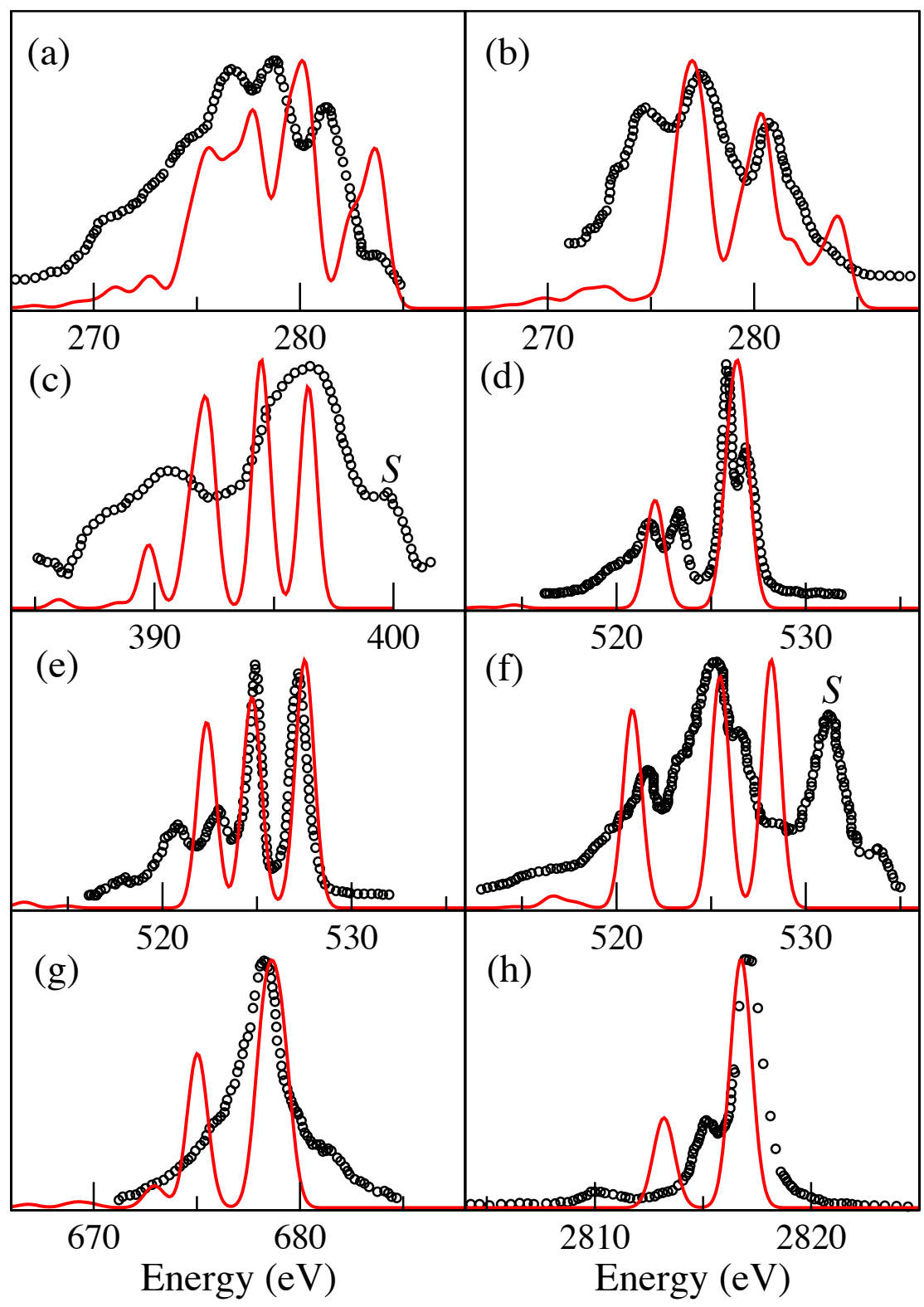

Figure 2: Experimental (circles) and calculated $\mathrm{B}^{66} \mathrm{LYP} / \mathrm{cc}-\mathrm{pCVTZ}$ (red lines) X-ray emission spectra for (a) C- $K$ fluorobenzene (b) C- $K$ nitrobenzene (c) N-K nitrobenzene (d) $\mathrm{O}-K$ acetone (e) $\mathrm{O}-K$ dimethyl sulfoxide (f) $\mathrm{O}-K$ phenol (g) F- $K$ fluorobenzene and (h) $\mathrm{Cl}-K \mathrm{CF}_{3} \mathrm{Cl}$. Experimental data. ${ }^{58-61} S$ indicates satellite lines due to multielectron processes and the theoretical spectrum for $\mathrm{CF}_{3} \mathrm{Cl}$ has been shifted by $+7.9 \mathrm{eV}$ to account for relativistic effects. 
For Table of Contents

Quantum Chemical Calculations of X-ray Emission Spectroscopy

by Jack D. Wadey and Nicholas A. Besley

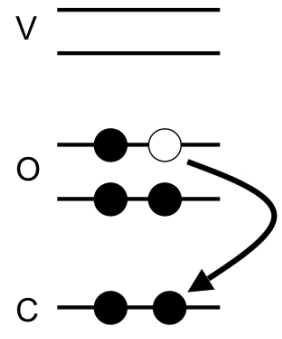

X-ray emission spectroscopy
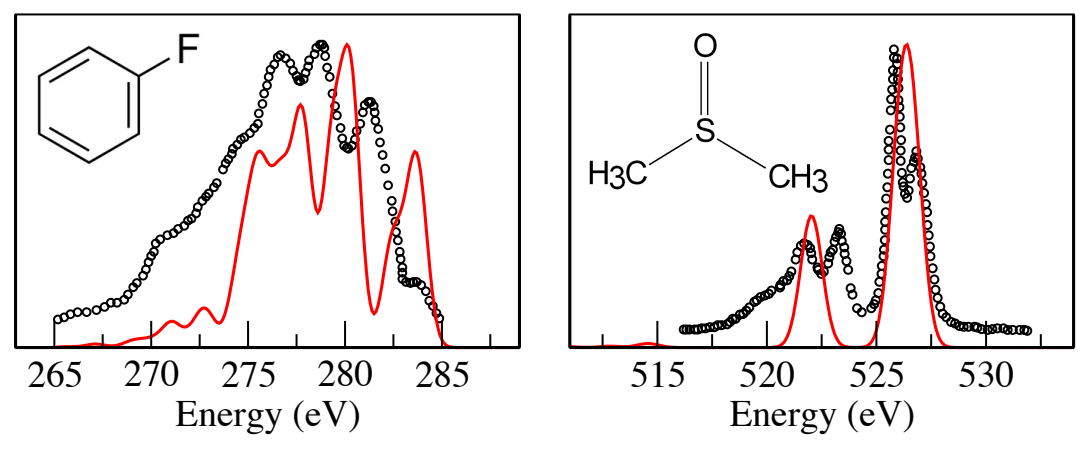